\title{
Підвищення точності неінвазивного вимірювання артеріального тиску осцилометричним методом
}

\author{
Зубков С.В., інженер \\ szub284@gmail.com \\ Козій M.I., acnipaнm \\ mykolakoziy@ukr.net \\ Кафедра біомедичної інженеріі \\ Національний технічний університет України \\ "Київський політехнічний інститут імені Ігоря Сікорського” \\ Київ, Украӥна
}

\begin{abstract}
Реферат - Розглянуто практичні апаратні рішення щзодо виділення пульсацій тиску в манжеті, щзо дозволяють підвищити точність та захищеність від перешкод алгоритмів вимірювання тиску. Досліджено вплив АЧХ фільтрів виділення слабких пульсаиій тиску в манжеті на форму вихідного сигналу в неінвазивних автоматичних вимірювачах артеріального тиску.

Під час розробки каналу неінвазивного вимірювання тиску для приліжкового монітору виявлено невідповідність між формою кривих пульсачій тиску в манжеті, отриманих прямою високоточною реєстрацією абсолютного тиску, з формою відповідних осцилячій. Виконано моделювання в МісгоСар-12 схеми каскаду виділення пульсацій тиску, яке підтвердило, що форма і амплітудні характеристики вихідного сигналу залежить від ЧСС.

Висновки: проектування каналу виділення пульсачій тиску в манжеті рекомендується виконувати у вигляді смугового фільтру, формулюючи вимоги щзодо нього у часовій області (до гладкості імпульсної перехідної функції), як більш значущі у даному разі, ніэж частотні.

Ключові слова: артеріальний тиск, осцилометричний метод, пульсаиії тиску, схемотехніка неінвазивного каналу
\end{abstract}

\section{І ВСТУП}

Переваги та недоліки осцилометричного методу добре відомі $[1, \ldots, 5]$. Слабким місцем методу $\epsilon$ недостатня захищеність від артефактів, пов'язаних 3 м'язовою активністю при рухах руки, або іï переміщенні. Спектр цих перешкод тягнеться від кількох герц до кількох десятків герц. Застосування високочастотних фільтрів для вирішення цього завдання в каналі виділення пульсацій тиску обмежено тим, що такі фільтри принципово у часовій області змінюють вигляд вхідного сигналу. Іншою важливою характеристикою каналу вимірювання неінвазивного тиску $є$ абсолютна похибка, на величину якої істотно впливають апаратна похибка вимірювання статичного тиску та похибка алгоритму визначення систолічного та діастолічного тисків. Якщо 3 огляду на доступність високоточних компонентів і великої кількості схемних рішень, забезпечення необхідної статичної точності сьогодні важливих труднощів не представляє, то з другою обставиною не все так очевидно. Основою коректності будь-якого алгоритму $є$ використання для його побудови адекватної інформації про інформативну ознаку, в даному випадку - амплітуду та форму пульсацій. Їхня величина становить всього кілька мм. рт. ст. У фундаментальній праці Н.Н. Савицького [6] вони чудово описані. У роботі викладено підхід до побудови каналу вимірювання тиску, в якому поєднуються підвищена захищеність від перешкод i коректність відліку тиску в манжеті, особливо, коли він збігається з моментом пульсації тиску.

\section{II. ПОСТАНОВКА ЗАДАЧІ}

Задачею роботи є дослідження впливу АЧХ фільтрів для виділення слабких пульсацій тиску в манжеті на форму вихідного сигналу в неінвазивних автоматичних вимірювачах артеріального тиску.

\section{III. СПОТВОРЕННЯ ФОРМИ СИГНАЛУ ДИФЕРЕНЦЮЧИМИ ВЛАСТИВОСТЯМИ ФВप}

При розробці каналу неінвазивного вимірювання тиску для приліжкового монітору було виявлено невідповідність між формою кривих пульсацій тиску в манжеті, отриманих прямою високоточною реєстрацією абсолютного тиску, 3 формою відповідних осциляцій, наведених в [6], [8], Рис.1. 


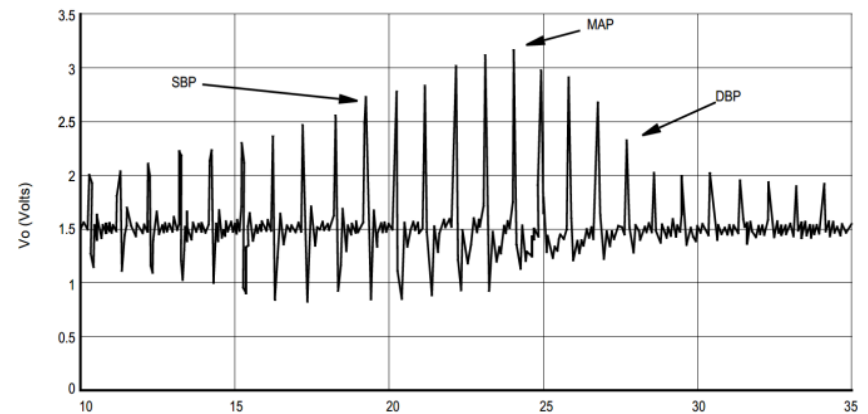

Рис.1. Форма пульсацій тиску в манжеті з [8] .

Форма реальних пульсацій тиску області систолічних значень виявилася близькою до $\mathrm{P}(\mathrm{t})=\operatorname{Sin}^{2 \mathrm{n}}(2 \pi \mathrm{ft})$, де $\mathrm{n}-$ ціле.

Припущення про відсутність негативних значень пульсацій (відносно усередненої кривої тиску в манжеті за вирахуванням пульсацій) засноване на тому, що енергія пульсуючої крові у фазі діастоли в артерії добре задемфована тканинами в місці вимірювання, і недостатня для подолання усредненого тиску. Крім того, передавальна функція проміжної ланки (манжети і повітропроводів) являє собою дві аперіодичні ланки [7] 3 порівняно великими постійними часу, що повільно змінюються. Це припущення потім повністю підтвердилося у багото-чисельних експериментах.

У [8] наведено схему каскаду виділення пульсацій тиску (рис. 2) та іï АЧХ (рис. 3). Сполучні частоти рівні:

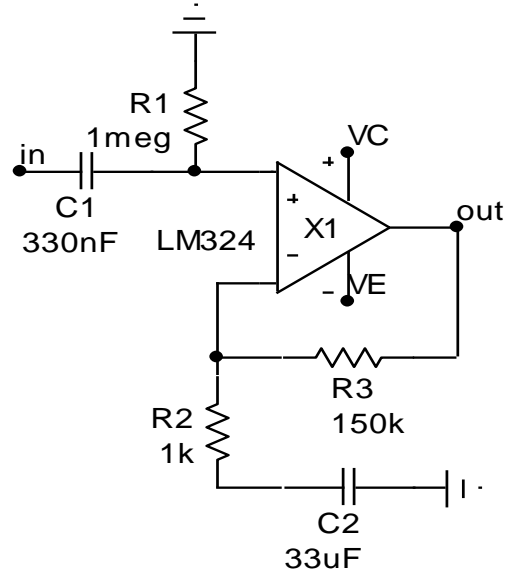

$$
f_{1}=\frac{1}{2 \pi R_{1} C_{1}}=0,04 \mathrm{~Hz}, \quad f_{2}=\frac{1}{2 \pi R_{2} C_{2}}=1 \mathrm{~Hz}
$$

Рис. 2. Схема підсилювача виділення пульсацій тиску в манжеті (ФВЧ з AN1571).

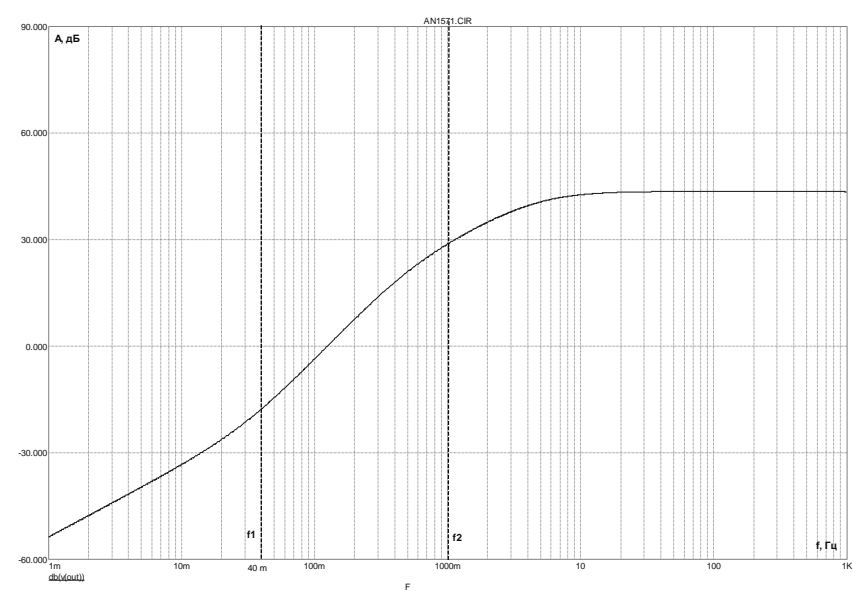

Рис. 3. АЧХ підсилювача пульсацій (ФВЧ з АN1571).

Моделювання цього вузла в MicroCap-12 підтвердило: форма (i амплітудні характеристики) вихідного сигналу залежить від ЧСС, що добре видно на наступному рис. 4 (жирні криві). На вхід каскаду подавався сигнал виду $\quad \mathrm{U}(\mathrm{t})=0.01 \operatorname{Sin}^{8}(2 \pi \mathrm{ft}), \quad \mathrm{f}=0.5 \quad$ Гц $\quad$ (верхній графік) та 3 Гц (нижній графік).

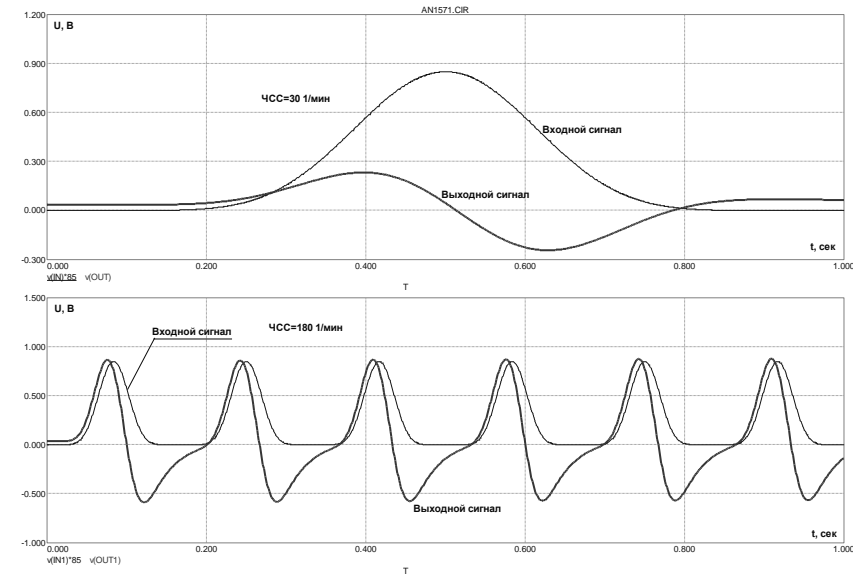

Рис. 4. Результати моделювання підсилювача пульсацій у часовій області (ФВЧ з АN1571).

I хоча тут взяті крайні випадки, ясно, що для адекватного відображення пульсацій тиску в манжеті потрібен фільтр, що не спотворює раніше згадану форму сигналу, що допускає каскадування i, бажано, смуговий - для підвищення стійкості до перешкод.

Варіант схеми нелінійного смугового фільтра показаний на рис. 5, а його нормована АЧХ і перехідні процеси при робочому циклі вимірювання артеріального тиску представлено на рис. 6 і рис. 7 відповідно. 


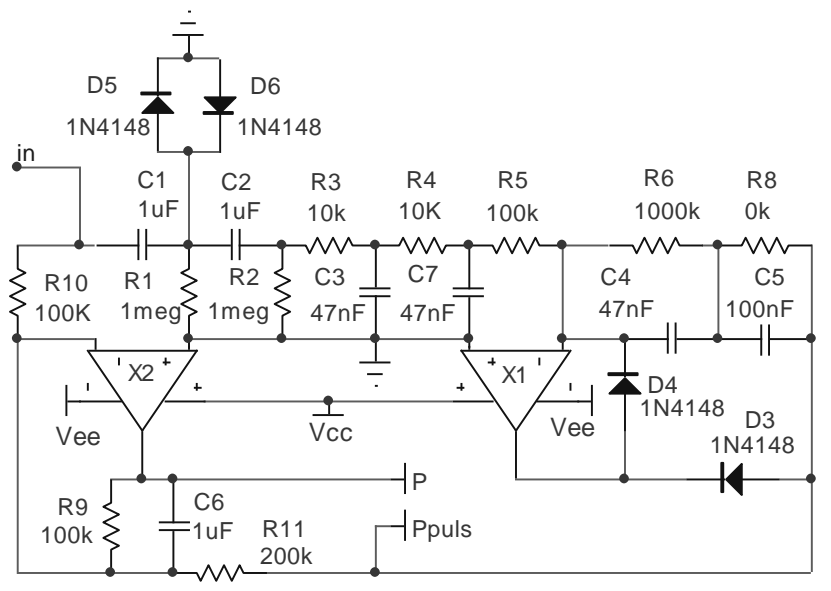

Рис. 5. Схема підсилювача пульсацій.

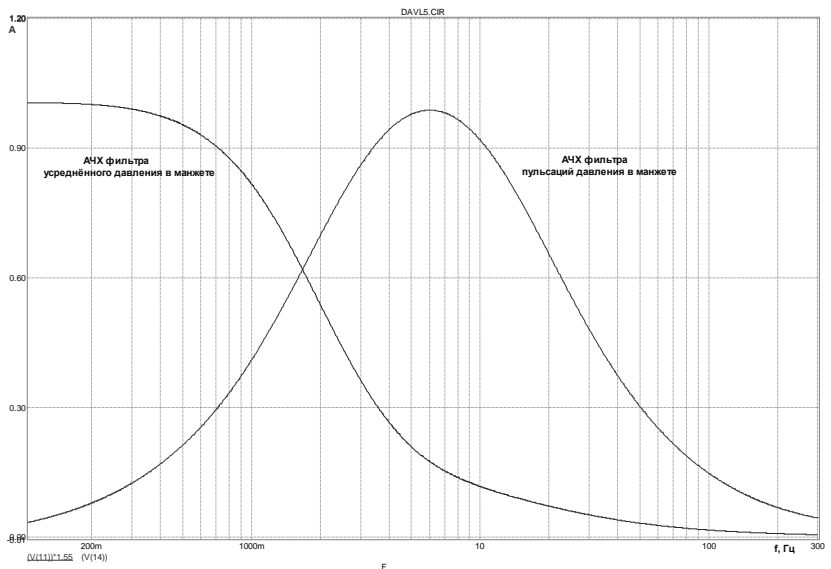

Рис. 6.АЧХ підсилювача пульсацій.
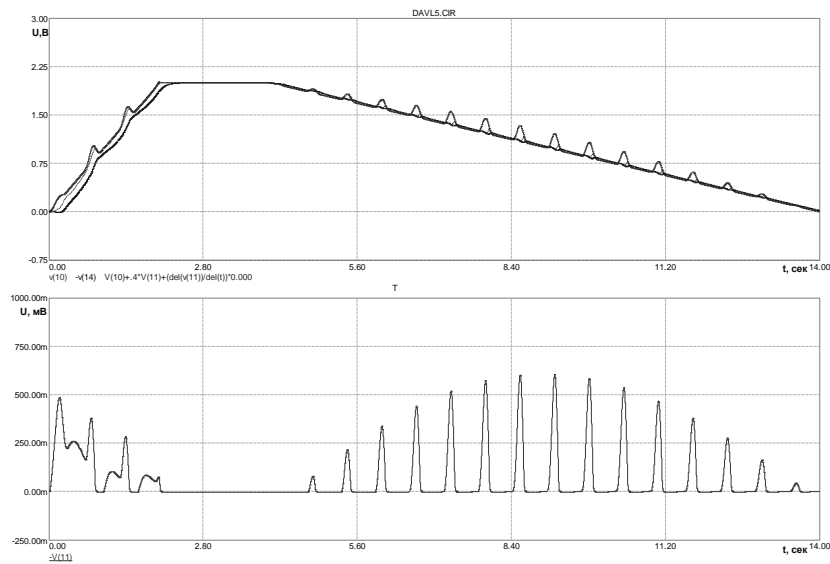

a

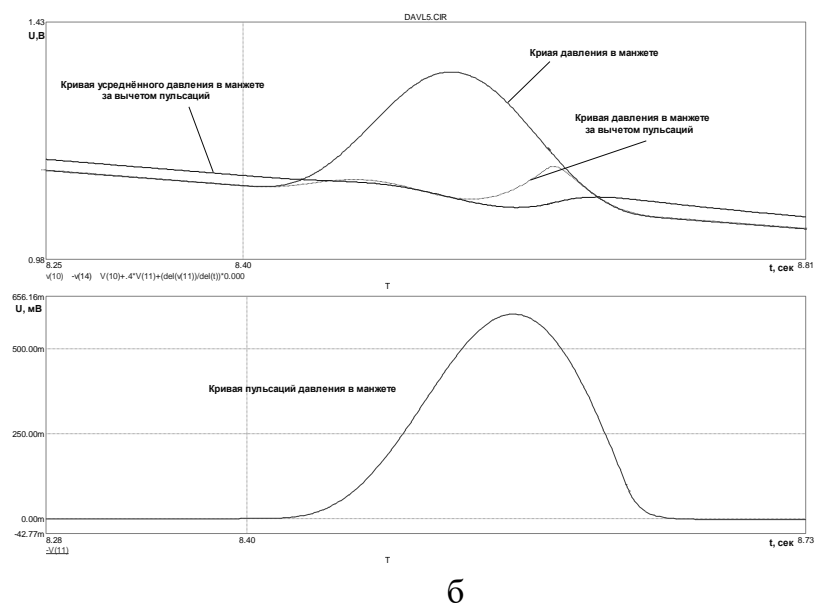

Рис. 7. Робочий цикл вимірювання тиску (а: криві тиску в манжеті та усереднена крива тиску - верхній графік, i криві пульсацій тиску - нижній графік; б: збільшений фрагмент рис.7a).

Видаливши зі схеми на рис. 4 діоди D3 та D4, отримуємо лінійний фільтр пульсацій тиску, вихідний сигнал якого представлено на рис. 8. Це підтверджує спотворення форми сигналу фільтрами ФВЧ (рис. 1).

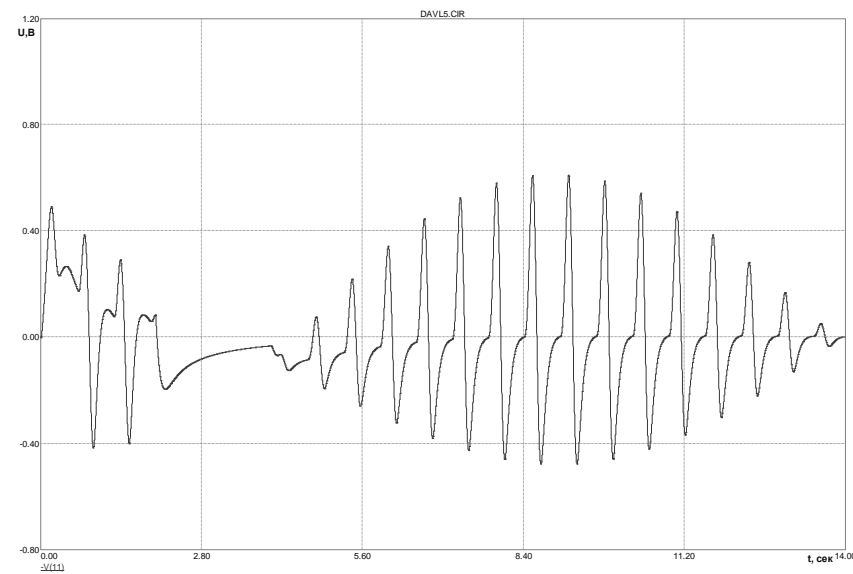

Рис. 8. Криві пульсації тиску в робочому циклі вимірювання тиску при лінійній фільтрації.

На виході підсилювача Х2 формується усереднений сигнал тиску $\mathrm{P}$ в манжеті за винятком пульсацій (Ppuls).

Натурний експеримент 3 цифровою реєстрацією тиску в манжеті пацієнта М.К. зі створенням в MicroCap-12 відповідного джерела сигналу $\mathrm{U} 1$, лінійною фільтрацією пульсацій та аналоговим формуванням огинаючої пульсацій, схема якого наведена на рис. 9, підтвердив правильність обраного підходу щодо проектування каналу неінвазивного вимірювання артеріального тиску. 


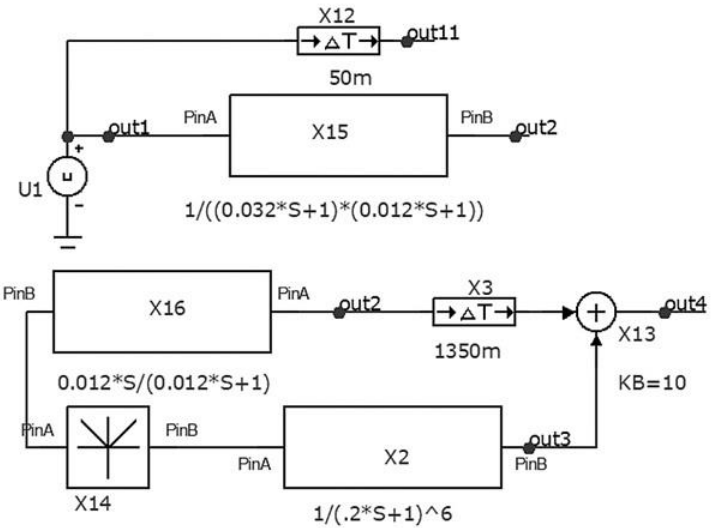

Рис. 9. Алгоритм виділення пульсацій та отримання огинаючої пульсацій.

Результати натурного експерименту наведено на рис.10. Запропоноване рішення дозволило 3 успіхом використовувати 14-ти розрядний АЦП для реєстрації пульсацій тиску, особливо не дбаючи про захищеність апаратної частини від перешкод.

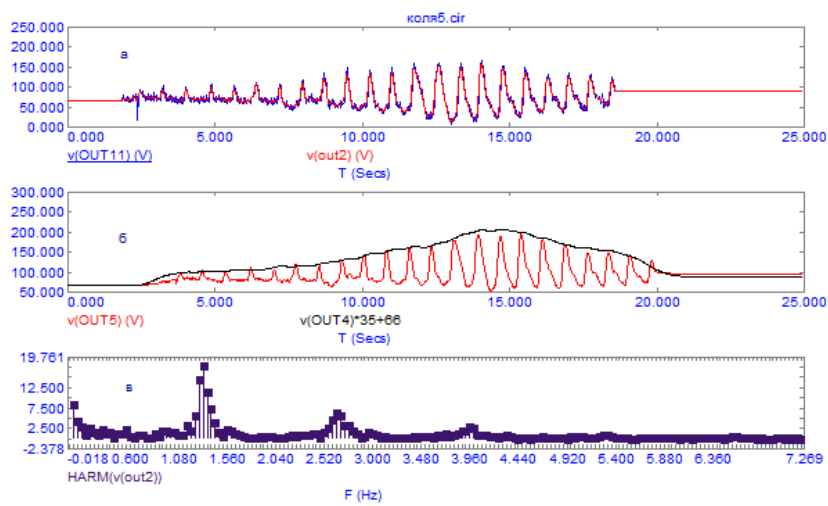

Рис.10. Результати натурного експерименту: a - графіки вхідного сигналу (синя крива) та профільтрованого сигналу (червона крива); б - відфільтрований сигнал пульсацій тиску з огинаючою (чорна крива); в - спектр відфільтрованого сигналу.

Запропонований лінійний фільтр пульсацій тиску з аналоговим формуванням огинаючої пульсацій (рис. 8) дає змогу значно підвищити рівень відповідності осцилометричного алгоритму визначення систолічного та діастолічного тисків значенням відповідних тисків за методом Короткова.

\section{IV. ВИСНОВКИ}

Моделювання в MicroCap-12 схеми каскаду виділення пульсацій тиску підтвердило, що форма і амплітудні характеристики вихідного сигналу залежить від ЧСС. Під час проектування каналу виділення пульсацій тиску в манжеті рекомендується виконувати його як смуговий фільтр, формулюючи вимоги щодо нього у часовій області (до гладкості імпульсної перехідної функції), як більш значущі у даному разі, ніж частотні.

\section{ПЕРЕЛІК ПОСИЛАНЬ}

1. Суточное мониторирование артериального давления при гипертонии. Под ред. Арабидзе Г.Г. и Атькова Ю.А. //РКНВК МЗ РФ, М., 1998г.

2. Фолков Б., Нил Э. Кровообращение. Пер. с англ.// М., «Медицина», 1976г., $463 \mathrm{c}$.

3. Джонсон П. Периферическое кровообращение. Пер. с англ. Под ред. Г.И. Косицкого. // М., «Медицина», 1982. $440 \mathrm{c}$.

4. Рашмер Р. Динамика сердечно-сосудистой системы. Пер. с англ. Под ред. Г.И. Косицкого. //М., «Медицина», 1981г., $600 \mathrm{c}$.

5. Каро К., Педли Т., Шротер Р., Сид У. Механика кровообращения. Пер. с англ. Под ред. С.А. Регирера, В.М. Хаютина.// М., «Мир», 1981. 624 с.

6. Савицкий Н.Н. Биофизические основы кровообращения и клинические методы исследования гемодинамики.//Л., «Медицина», 1974г., 311с.

7. Ордынцев В.М. Математическое описание объектов автоматизации. //М., «Машиностроение», 1965г. 260 с.

8. Digital Blood Pressure Meter. Freescale Semiconductor Application Note. AN1571.// [Електронний ресурс] Режим доступу до ресурсу: https://www.nxp.com.cn/docs/en/applicationnote/AN1571.pdf 
УДК 612.141

\title{
Повышение точности неинвазивного измерения артериального давления осциллометрическим методом
}

Зубков С.В., инженер szub284@gmail.com

Козий Н.И., аспирант mykolakoziy@ukr.net

Кафедра биомедицинской инженерии Нацииональный технический университет Украины

"Киевский политехнический институт имени Игоря Сикорского"

Киев, Украина

Реферат - Рассмотрены практические аппаратные решения по выделению пульсаций давления в манжете, позволяющие повысить точность и защищенность от помех алгоритмов измерения давления. Исследовано влияние АЧХ фильтров на выделение слабых пульсаиий давления в манжете на форму выходного сигнала в неинвазивных автоматических измерителях артериального давления.

При разработке канала неинвазивного измерения давления для прикроватного монитора обнаружено несоответствие между формой кривых пульсаиий давления в манжете, полученных прямой высокоточной регистрацией абсолютного давления, с формой соответствующих осииллящий. Выполнено моделирование в МісгоСар-12 схемы каскада выделения пульсаций давления, подтвердивщее, что форма и амплитудные характеристики выходного сигнала зависят от ЧСС.

Выводы: проектирование канала для выделения пульсаиий давления в манжете рекомендуется выполнять в виде полосового фильтра, формулируя требования к нему во временной области (к гладкости импульсной переходной функиии), как более значимые в данном случае, чем частотные.

Ключевые слова: артериальное давление, осциллометрический метод, пульсации давления, схемотехника неинвазивного канала.

UDC 612.141

\section{Improving the accuracy of non-invasive blood pressure measurement by the oscillometric method}

\author{
Zubkov S.V., engineer \\ szub284@gmail.com \\ Koziy M.I., graduate student \\ mykolakoziy@ukr.net \\ Department of Biomedical Engineering \\ National Technical University of Ukraine \\ Igor Sikorsky Kyiv Polytechnic Institute \\ Kyiv, Ukraine
}

Summary - Practical hardware solutions for pulsation are considered cuff pressure to increase the accuracy and interference protection of pressure measurement algorithms. The effect of the frequency response of the filters on the selection of weak pulsations of pressure in the cuff on the shape of the output signal in non-invasive automatic blood pressure meters was investigated.

When developing a channel for non-invasive pressure measurement for a bedside monitor, a discrepancy was found between the shape of the cuff pressure pulsation curves obtained by direct high-precision recording of absolute pressure, with the shape of the corresponding oscillations. The simulation in MicroCap-12 of the circuit of the cascade of pressure pulsation extraction has been carried out, which has confirmed that the shape and amplitude characteristics of the output signal depend on the heart rate.

Conclusions: it is recommended to design a channel for measurement pressure pulsations in the cuff in the form of a band-pass filter, formulating the requirements for it in the time domain (to the smoothness of the impulse transient function) as more significant in this case than frequency ones.

Key words: blood pressure, oscillometric method, pressure pulsations, non-invasive channel 